\title{
CORRECTION
}

\section{Correction: Specific post-translational histone modifications of neutrophil extracellular traps as immunogens and potential targets of lupus autoantibodies}

\author{
Chih L Lii'1,4, Stephanie Tangsombatvisit', Jacob M Rosenberg', Gil Mandelbaum', Emily C Gillespie², Or P Gozani, \\ Ash A Alizadeh ${ }^{3 *}$ and Paul J Utz ${ }^{1 *}$
}

See related research by Liu et al., http://arthritis-research.com/content/14/1/R25

\section{Correction}

After publication of our recent article [1], it has been brought to our attention that the incorrect wording was used to acknowledge our EU funding source. The correct statement should read:

"The research leading to these results has received funding from the European Union Seventh Framework Programme (FP7/2007-2013) under grant agreement $n^{\circ}$ 261382."

\section{Author details}

'Department of Medicine, Division of Immunology and Rheumatology, Stanford School of Medicine, 269 Campus Drive, Stanford, California 94305, USA. ${ }^{2}$ Center for Immunology, University of Minnesota Medical School, 420 Delaware Street SE, Minneapolis, Minnesota, 55455, USA. ${ }^{3}$ Department of Medicine, Division of Oncology and of Hematology, Stanford School of Medicine, 300 Pasteur Drive, Stanford, California 94305, USA. ${ }^{4}$ Department of Biology, Stanford University, 371 Serra Mall, Stanford, CA 94305, USA.

\section{Reference}

1. Liu C, Tangsombatvisit S, Rosenberg J, Mandelbaum G, Gillespie W, Gozani O, Alizadeh A, Utz P: Specific post-translational histone modifications of neutrophil extracellular traps as immunogens and potential targets of lupus autoantibodies. Arthritis Res Ther 2012, 14:R25

Published: 14 August 2012

doi:10.1186/ar3933

Cite this article as: Liu CL, et al:: Correction: Specific post-translational histone modifications of neutrophil extracellular traps as immunogens and potential targets of lupus autoantibodies Arthritis Research \& Therapy 2012, 14:403.
*Correspondence: arasha@stanford.edu; pjutz@stanford.edu

'Department of Medicine, Division of Immunology and Rheumatology, Stanford School of Medicine, 269 Campus Drive, Stanford, California 94305, USA

${ }^{3}$ Department of Medicine, Division of Oncology and of Hematology, Stanford

School of Medicine, 300 Pasteur Drive, Stanford, California 94305, USA

Full list of author information is available at the end of the article 